\title{
Domestic Violence Against Women in Bangladesh: Nature, Reasons and Policy Guidelines
}

\author{
A.H.M Mahbubur Rahman ${ }^{1 *} \quad$ Matiur Rahman $^{2}$ \\ 1.Assistant Professor and Chairman, Department of Social Work, Bangamata Sheikh Fajilatunnesa Mujib \\ Science \& Technology University (BSFMSTU), Jamalpur, Bangladesh \\ 2.Research Consultant, Human Development Research Centre (HDRC), Dhaka, Bangladesh
}

\begin{abstract}
Domestic violence is a pattern of assault and coercive behavior including physical, sexual and psychological attacks, by a person against his/her own intimate partner. Women are more frequently the victims. Domestic violence against women in Bangladesh is a major social problems and barriers to national development. In a patriarchal society like Bangladesh woman always remain subordinate to male and sometimes become victim of repression. This article provides a scenario of different forms of domestic violence against women. As well as reasons of domestic violence i.e., social, cultural, traditional, religion, economical, legal and psychological were also explored and some policy guidelines have been suggested.
\end{abstract}

Keywords: Domestic Violence, Woman, Empowerment, Bangladesh

DOI: $10.7176 /$ RHSS/11-8-02

Publication date: April $30^{\text {th }} 2021$

\subsection{Introduction}

Domestic violence (Violence against women or girl in the home or family environment) is a foremost social problem in Bangladesh. Domestic violence incidences are very much common occurring in society frequently. Women of all social and economic strata are being abused by husbands, in-laws, and other family members. Available data suggest that the number of cases of domestic violence is increasingly being reported in the newspapers, though a major portion remains unreported. Domestic violence is the domain of the umbrella term 'Gender Based Violence' (GBV) perpetuated on women only. It is estimated that about 50 to 60 per cent women in Bangladesh have experienced some form of domestic violence (ICDDR,B, 2006).

In Bangladesh, at this age of easy access to information, we are encountering some horrifying facts happening in the form of domestic violence. Specially, print and electronic media are quite alert to bring out these facts before the people. From our general observation it can be pointed out that, domestic violence against women is quite a common phenomenon in Bangladesh. This is largely due to the existing patriarchal social system where men play dominating role in the society and on economic resources. Prevalence of favorable values neglects women's rights, opposes women's freedom at the same time, promotes and provokes men to subjugate and oppress women. As a result, patriarchy tends to trigger and intensify different forms of violence against women that take place in our society (Karmakar, Ranjan (ed.), 2003). Domestic violence is still considered a "personal matter" and ignored by the community.

Domestic violence is generally perpetrated by husbands, but may also involve other relatives. In Bangladesh, domestic violence against women is closely linked to the institution of marriage (Koenig A. Michael et.al, 2003). Marriage related norms and practices reinforce women's relative powerlessness, often exposing them to domestic violence. Domestic violence is often used to establish and enforce gender roles early in marriage, and very young women may be particularly vulnerable and unable to resist.

This paper has been tried to explore the nature and/or forms of domestic violence against women in two villages in Jhenaidah district. It has also addressed the factors leading to that violence with the objective to suggest some policy guidelines for avoiding such a crime.

\subsection{The Objectives}

The specific objectives of the present research are:

1. To review the nature and/ or forms of domestic violence against women in the study villages

2. To explore the socio-economic and cultural factors responsible for domestic violence against women in the study villages.

3. To identify areas for action and formulate policy guidelines on the basis of the findings.

\subsection{The Research Methods}

The present paper has been prepared based on data collected from field for a study. Social survey method was used in this research to collect quantitative data. Data were collected using a set of structured questionnaire. By using a two-stage stratified random sampling procedure 85 female respondents were selected for interview. The study was carried out in two villages in Jhenaidah sadar upazila of Jhenaidah district. 


\subsection{Nature of Domestic Violence against Women in the Study Villages}

To reveal the nature of domestic violence against women in the study villages some indicators were set and gathered answers from the interviewees. Their opinion is analyzed below.

Verbal abuse: Verbal abuse is a very common form of domestic violence. Verbal abuseis best described as an ongoing emotional environment organized by the abuser for the purposes to control. The underlying factor in the dynamic of verbal abuse is the abuser's low regard for him or herself. As a result, the abuser attempts to place their victim in a position to believe similar things about him or herself, a form of warped projection.Abbas Bhuiya and others have showed that 66.8 per cent of women were verbally abused by their husband and 23.7 per cent by other family members (Bhuiya, Abbas et.el, 2003). They have also revealed that to most of the women verbal abuse is a daily matter and husband use demeaning words as verbal abuse. In the present research a large majority of female respondents $(82.3 \%)$ from both the villages admitted that they were verbally abused by their husbands and other family members. Thus, in the present research comperatively more women have reported that they became victims of verbal abuse. They have also mentioned that their husbands sometimes use some humiliating words to keep them under control.

Battering/Physical hurt: Battering is a pattern of behavior used to establish power and control over another person through fear and intimidation, often including the threat or use of violence. It is an extreme stage of violence against women after verbal abuse. Battering happens when one person believes they are entitled to control another. Battering or physical hurt is also a common form of domestic violence on women. It has been found that for the present study a slightly over one third (34.1\%) women experienced beating during last one year by their husband. The proportion is high in village Sonatonpur where around 46 per cent women have experienced beating during last one year.

There are some other forms of domestic violence against women have also been revealed from the study. Those are: breaking of household assets to show anger upon women, threatening with weapon, depriving the women from household assets, deprivation from food/meal, preventing them from doing household works, threatening about divorcing, insulting inside and outside the home,husband provoked others to insult or making misbehave with her, husband forced doing sex against their will, blaming of involving illegal relations with someone, preventing them from visiting parent's house, keeping away child from mothers, create pressure to bring dowry, provoked to commit suicide, threat of murder, tortured for not giving dowry, stopped talking and so on. The surveyed women consider all those type of violence as domestic violence happened upon them in their life time within the family atmosphere.

\subsection{Reasons of Domestic Violence against Women in the Study Villages}

It has been found that several factors or reasons are responsible for domestic violence on women in the study villages. The respondents have mentioned some certain cultural, economical and legal reasons that promote domestic violence against women. The following section describes those reasons in detail.

1.5.1 Custom, culture, tradition, religion and psychological reasons of domestic violence

Defying Parents or Older: Obeying older or respectable person is a normative culture in our society. Usually no one could challenge the power and authority of the elder or very respectable person of the society. It is believed that women should always obey the older. But if any one of them dares to challenge the power and authority of the older then society cannot bother it and give punishment to her or them. In the present research a large majority of the female respondents $(88.2 \%)$ have mentioned that women tortured if they defy their parents or other older people in the household.

Showing Ignorance towards 'Murubbi': It is an established form of the society that women will always obey the Murrubbi whether they do right or wrong. If anyone disobeys them then she will be punished. It has also been found that a very large portion of female respondents $(87.1 \%)$ mentioned that female or women in the household are beaten up or repressed if they show ignorance towards Murubbi or disobey Murubbi (very respectable person).

Arguing with male: Arguing with male by female is not acceptable in our society. It is always think that female will not make any argument with her husband or other male member of the society. They only carry out the order and follow her husband and other male member of the family. But if she makes any arguments in any matter then she will be punished. From the present survey it has also been found that a large share of female respondents $(88.2 \%)$ has mentioned that females are beaten or oppressed if they argue with male member of the family.

Making quarrel with Neighbors: Making quarrel with neighbors is a common scenario in rural Bangladesh. But society still could not accept it as a good norm. If any women makes quarrel with neighbors then she is blamed and tortured by their husband or male counterpart.

In the present study it has been found that around $88.2 \%$ of the female respondents indicated quarrel with neighbors as a reason of domestic violence.

Keeping relation with other male: Keeping relation with other male is considered as a fault in our society. So, whenever, a girl or women get involved in such type of relationship without the permission of parents or 
husband then she or they blamed and get punishment. In the present study around $92.9 \%$ of female respondents have mentioned that female of household are oppressed or beaten up if they (wife or daughter) keep relation with others male without the permission of husband or parents.

Continuation of relation with other male in spite of warning: It is expected that women will not get involve any relationship with any male outside their family member. If someone involved in such relationship then their father, brothers or husband give warning her to give up the relationship. But if anyone do not pay heed to them then she or he become punished. In the present research it has been found that a large majority of female respondents $(83.5 \%)$ mentioned that females are beaten up or oppressed if they continue relation with others male after warning her / them.

Not taking care of ill husband: It is expected that wife always will take care of her husband. If she does not do it then it is very intolerable to the male member of the family and they beat her/them. In the present study a large portion $(88.2 \%)$ of female respondents agreed that females (wife) are beaten / tortured if she / they do not take care of their ill husband.

Disobeying order of male: Disobeying any order of male is also considered as disloyalty of female to male. As society people always expect that female will carry the order of male. So, when they fail to do that they become victim of domestic violence. In the present research about 90 per cent of female respondents agreed that females (wife / daughter) are beaten / tortured if she / they do not listen any word after giving her / them re- warning.

Fail to prepare and delivery of meal/ food timely: In our society cooking and delivery of meal is considered as the work of female. If they fail to do that, they are punished. From the present survey it has been revealed that around 86 per cent of respondents mentioned that females (wife) are beaten / tortured if her / their husband does not get meal timely after returning outside work.

Washing husband's dress/cloth: Like preparation of food washing clothes is also the duty of women in household level. If anyone cannot do the work then she blamed and punished. In the present survey it has been found that a large majority of the female respondents $(85.9 \%)$ mentioned that females (wife) are beaten / tortured if she / they do not wash their husband's dress / cloth timely.

Refusal of doing sex according to husband's will: In our society if any male got married then he think that his wife is bound to do sex with him anytime and anywhere. He also thinks that he has the full right over his wife to do sex although she is not ready to do it at that time. In that case, if any wife does not agree to do sex according to the demand of the husband then she is punished. From the present study it is revealed that around 86 per cent of female respondents mentioned that wife are beaten / tortured if she / they do not do sex according the will of her / their husband.

Bad performance in household work: Traditionally women in the household do all the works. So, they have to show efficiency and skill in household works. If she does it successfully then everyone praise her but if someone cannot do it then she is blamed and her male counterpart tortures her. While surveyed in field level it has been revealed that around 87 per cent of the female respondents mentioned that females (wife/ daughter) are beaten / tortured if she / they do not complete the household works according the choice of their husband / parents.

Husband relationship with other female: Naturally, at conjugal life no wife wants that her husband get involve with other women. If any wife doubt her husband and make any query about such type of relationship then she become victim of domestic violence.In the present survey it has been revealed that over three-fourth $(75.3 \%)$ of the female respondents agreed that females (wife) are beaten / tortured if she / they want to know about a relationship of her husband with other female.

Suspect of parents or husband: In our society women are always the subject of suspecting. If her parents or husbands think that her daughter or wife are hiding something to them then she blamed and get punishment. In the present 76.3 per cent of the female respondents mentioned that females (wife/daughter) are beaten / tortured if husband / parents doubt her / them on any issue.

Becoming Faithless: If any women or girl become unfaithful then the other members of the family give punishment to her. From the present research it has been found that 84.7 per cent of the female respondents agreed that females (wife/daughter) are beaten / tortured if she / they become unfaithful to her/their husband or parents and to other family members.

Not maintaining 'Purdah' or wearing 'Burkha': Bangladesh is a male dominated Muslim country where women are expected to maintain 'Parda' while they go outside or encounter unknown male person. It is also expected that women always will wear 'Burkha' (rapping with black cloth) while they go outside home. If someone does not follow this rule, she is blamed. In the present research it has been found that 84 per cent of the female respondents agreed with this statement that 'Females (wife/daughter) are beaten / tortured if she / they do not wear Burkah (wrapping with black cloth)'.

Unable to cook food according to the choice of husband: It is also considered in our society that cooking good and tasty food is the duty of women. If anyone failed to do that then she is blamed. From the present research it has been revealed that around 74 per cent of the female respondents said that females (wife) are beaten / tortured if she cannot cook good food according to the choice of her husband. 
Inability to give birth of a male child: In our society women are blamed if she could not give birth of a male child. Sometimes they are punished for this. In the present research it has been found that 71 per cent of the female respondents agreed that females (wife) are beaten / tortured if she could not give birth a male child.

To show male power and authority over female: It is very established in our society that male are supreme. They are stronger than female and they can do everything they wish. Women are their subordinate. From this view sometimes they torture their female partner to show their power and authority. In the present research it has been found that 76 per cent of the female respondents from both the villages agreed that male beats / tortures female to show their power and authority on female.

Inability to provide dowry according to the demand: Within the marriage in our country dowry giving is a common practice. In rural areas it is more acute. If the parents of the bride cannot give dowry according to the demand of the groom's demand then many questions are raised and husband tortured his wife for dowry. In the present research a majority of the female respondents (76\%) agreed that females (wife/daughter) are beaten / tortured if her / their guardians could not give sufficient dowry according the demand of the husband or his parents.

Underestimating women power: In our society, men always perceived that female are physically weak and they are always dependent upon male. They have no power to protest men. From this misperception sometimes male torture female. In the present study it has been revealed that around 82 per cent of the female respondents agreed that male beats/tortures women bearing this perception in their mind that 'women would not protest'.

Visiting or living of wife's relative in husband's house: In our society it is unexpected that parents or brothers or sister of wife are living in wife's father in law house. Society people do not see it in a good eye. As a result sometimes husband beat his wife. In the present research it has also been found that over three-fourth $(75.6 \%)$ of the female respondents agreed that females (wife) is beaten / tortured if her parents, brothers or sisters come to visit or live permanently to her husband house.

Acceptance of Education and intelligence of women: In our society most of male think that female should not achieve higher education because if any female achieved higher education then they do not obey their husband. So, due to higher education and intelligence of female sometimes male torture them. In the present study it has been found that a large majority of the female respondents agreed that male cannot accept female's higher education, awareness and capacity of taking decision to anything so they become victim of male's torture/ repression.

Dark complexion of wife: In our country men always want to marry a female who has fare and bright complexion. So, sometimes female who does not have fare complexion suffer in her husband's house. From the present study it has been found that 87 per cent of the female respondents agreed that females (wife) is beaten / tortured if her husband does not like her due to dark complexion.

Demand of love or affection from the females: From the present research it has also been found that around $84.7 \%$ of the respondents indicated not growing love or affectionate to wife as a reason of domestic violence against women.

\subsubsection{Economical reasons}

Poverty: Poverty is a pivotal cause for domestic violence on women. In our country around $40 \%$ of the people live under poverty line. Poverty, higher rate of unemployment and gradually increasing livelihood cost create frustration among men. As a result sometimes they torture their wife physically and mentally. In the present research it has been found that around 77 per cent of the female respondents agreed with the statement that poverty, unemployment and increasing livelihood cost create frustration among male and they sometimes become frustrated and tortured their wife.

Expensing money without permission of husband, economical dependency on male, incapability of earning money, inheriting less property and women less participation in employment are also reported by the surveyed women as economic reasons of domestic violence against women in the study villages.

1.5.3 Legal reasons

Weak Legal System: The legal system in our country is not so strong. Sometimes, criminal get escape due to the gap of legal system. As a result criminal do not get punishment and they get chance to do crime again. A very large portion of women (96\%) respondents of the present study agreed that females (wife/daughter) tortured / beaten for the weak legal system in our country.

Lack of knowledge about Law: In our country majority of women both in rural and urban areas do not have sufficient knowledge about legal system and law. As a result they could not understand what type of legal help they/she can receive during any vulnerable situation within or outside the household. In the present research around 85 per cent of female respondents agreed that females (wife/daughter) tortured / beaten as they do not have sufficient knowledge about law or not getting proper legal support.

Reluctant attitude of law enforcing force: In most of the cases law enforcing agency of our country do not get strong steps to arrest the criminal. Sometimes, they harass the complainants. Moreover, the law enforcing agencies take money from the criminal and remain reluctant and silent. As a result, domestic violence continues 
in the society. A large majority of the respondents $(71 \%)$ of the present research agreed that females (wife/daughter) tortured / beaten as the law and order maintaining force sometimes show reluctant to such cases or sometimes they do not provide proper support to such cases.

There are also some empowerment related issues like less participation of women in development activities, giving less importance by family members, personal of family matters, insufficient women pressure creating organization, ignorance of men, etc are also revealed as reasons of domestic violence against women reported by the surveyed women.

\subsection{Policy Guidelines}

The results of the present research show that women in the study villages have been experiencing different types of domestic violence. On the basis of the above findings the following policy guidelines are suggested:

1. Measures should be taken to change social attitudes and beliefs that legitimize male violence and the notion of male superiority. Education, mass media campaign, street drama, etc. can play an important role in this regard. NGOs and government organizations also can take different programs to this end. There is a need to involve civil society, religious leaders in this regard.

2. Victims need to be provided with direct support, counseling and legal aid. Some form of counseling for men is also needed to raise their awareness on human rights and gender issues.

3. The issue of domestic violence against women should to be included in school curricula, at all levels, from primary to tertiary and vocational training.

4. All acts regarding violence against women (Domestic violence prevention and protection act, Acid control act, Dowry Prohibition act, etc) should to be strictly enforced with the provision for stringent punishment for offenders.

5. Economic empowerment of women is an important means to fight back at violence and injustice as it raises self-worth and supplement with resources to fight her battle. Therefore, girls will have to be given the necessary skill, training, education and employment opportunity so that they are capable of supporting themselves.

\section{Conclusion}

Although Bangladesh has attained remarkable success in increasing literacy rates for women, and decreasing the maternal and child mortality rate, violence against women is still very high in our society among which domestic violence is widely prevalent in both urban and rural areas as an everyday matter of women lives. The nature and causes of domestic violence identified in the present study ranges from verbal abuse to reluctant attitude of law enforcing agencies indicate the awful side of established patriarchal social system. The implementation of the suggested policy guidelines may break the system and equal opportunity could be ensured for women and domestic violence will be reduced and/or disappeared from Bangladesh Society.

\section{Reference:}

1. Abraham, Margaret (2000), Speaking the Unspeakable: Marital Violence among South Asian Immigrants in the United States, New Brunswick NJ: Rutgers University Press.

2. Nguyen Dang Vung (2008), Intimate Partner Violence in Rural Vietnam: Prevalence, risk-factors, health effect and suggestions for interventions, Stockholm, Sweden.

3. Ahmed SM (2005), Intimate Partner Violence against Women: Experiences from a Woman-focused Development Programme in Matlab, Bangladesh, Research and Evaluation Division, BRAC, Dhaka.

4. Ahmed, M. (1985), Status, Perception, Awareness and Marital Adjustment of Rural Women: The Role of the Grameen Bank, Paper No. 31, Grameen Bank, Dhaka.

5. Ameen, Nushrat (2005), Wife Abuse in Bangladesh: An Unrecognized Offence, The University Press Limited, Dhaka.

6. GOB (2007), Bangladesh Population Census, 2001, Dhaka: Bangladesh Bureau of Statistics, Ministry of Planning.

7. GOB (2007), Statistical Pocketbook of Bangladesh, 2006, Dhaka: Bangladesh Bureau of Statistics, Ministry of Planning.

8. Barkat, A (2007), Violence Against Women in Bangladesh: How Serious We Are? Paper presented at First National Conference on Achieving Millennium Development Goals 4 and 5: Where we are and what needs to be done, Institute of Child and Mother Health (ICMH NC-I) Dhaka.

9. Bates, LM, Schuler, SR, Islam F. (2004), Socioeconomic Factors and Processes Associated with Domestic Violence in Rural Bangladesh, International Family Planning Perspectives, 30: 190-199.

10. Bhuiya, Abbas, Sharmin, Tamanna and Hanifi, S.M.A (2003), "Nature of Domestic Violence against Women in a Rural Area of Bangladesh: Implication for Preventive Interventions", Journal of Health and Population, ICDDR, B: Centre for Health and Population Research, Dhaka. 
11. BNWLA (2003), Violence against Women in Bangladesh 2002, Bangladesh National Women Lawyer Association, Dhaka.

12. C. Garcia-Moreno, H, Jansen, M, Ellsberg, L, Heise, C, Watts (2005), WHO Multi-country Study on Women's Health and Domestic Violence against Women-Initial results on prevalence, health outcomes and women's responses, World Health Organization, Geneva, Switzerland. www.who.int/gender/violence/multicountry/en/index1.html

13. Jewkes, R. (2002), Intimate partner violence: causes and prevention. The Lancet 359: 1423-1429.

14. Karmakar, Ranjan (ed.) (2003). Domestic Violence against Women in Bangladesh, Steps Towards Development, Issue 2, Dhaka.

15. Koenig, Michael A, et. al (2003), "Women's Status and Domestic Violence in Rural Bangladesh: Individual and Community-Level Effects",Demography, 40(2): 269-88.

16. Mannan, MA (2002), Violence against Women: Marital Violence in Rural Bangladesh, Centre for Policy Dialogue, Dhaka.

17. Mannan, M.A (2004), Violence against Women: Marital Violence in Rural Bangladesh, CPD-UNFPA Paper No. 20, Dhaka.

18. Naripokkho and Bangladesh Mahila Parishad (2003), Baseline Report on Violence against Women in Bangladesh, International Women's Rights Action Watch Asia Pacific (IWRAW Asia Pacific), Kuala Lumpur, Malaysia.

19. National Institute for Population Research and Training (NIPORT) (2009), Bangladesh Demographic and Health Surveys 2007, Mitra and Associates, Dhaka, Bangladesh and Macro International, Calverton, Maryland, USA.

20. Naved, RT, Persson, LÅ. 2005, Factors Associated with Spousal Physical Violence Against Women in Bangladesh, Studies in Family Planning 35: 289-300.

21. UNICEF (2000), "Domestic Violence against Women and Girls", Innocenti Digest, Volume 6, June 2000, Unnocenti Research Center, Florance, Italy.

22. United Nations Children's Fund (2000), “Innocenti Digest", Issues 6, The Innocenti Research Center, Florence, Italy.

23. United Nations (1993), Declaration on the Elimination of Violence against Women', Paper presented at the Proceedings of the 85th Plenary Meeting., Geneva.

24. Goode, W.J. and P.K. Hatt (1952), Methods in Social Research, McGraw-Hill Book Company, Inc. International Student Edition, Tokiyo.

25. Zimmerman, Watts C (2002), "Violence against Women: Global Scope and Magnitude", Violence against Women, 350: 1232-1237.

26. WHO (2002), World Report on Violence and Health, World Health Organization. Geneva, Switzerland. 